\title{
The main system value orientations of the personality
}

\author{
Anastasia Kolenova, Marina Elagina, and Darya Kiseleva* \\ Don State Technical University, 344002, Rostov-on-Don, Russian Federation
}

\begin{abstract}
The article is devoted to the problem of systemic value orientations of the personality of girls who are officially and informally married. In the modern world, the values of the family are very strongly influenced by negative trends, non-observance of traditions, unstable marriages, and the collapse of moral norms. Creating a family and fostering values for modern society is a difficult task. The purpose of the study: to identify the value orientations of young girls who are in an informal and official marriage. The paper consistently solves the following problems: the concept of value orientations is considered; the position of the family in the system of value orientations of girls who are in an informal and official marriage is revealed; domestic and foreign approaches to the study of value orientations are compared. Research methods: theoretical and empirical methods were used to solve the tasks set. As a result of the conducted empirical research, the formulated hypothesis is proved, the following tasks are solved: the value orientations of girls who are in an informal and official marriage are compared; the meaning of girls ' lives is investigated; the degree of satisfaction with marriage is revealed.
\end{abstract}

\section{Introduction}

In the modern world, the values of the family are very strongly influenced by negative trends, non-observance of traditions, unstable marriages, and the collapse of moral norms. Creating a family and fostering values for modern society is a difficult task. Such qualities as: responsibility, respect for elders, love, loyalty, care, are manifested in marriage [2]. Moral principles and norms are formed in the family circle, and also manifest themselves in the behavior of people in public institutions: kindergartens, schools, universities, and at work. These values in a person revive the culture, make it humane [3].

Everyone has an extremely complex process of forming the values of the family and the union and the attitude towards them, in particular the younger generation. It is important to present and understand the values of young people. The young generation is a perspective, the formation of a positive image of family and marriage is of great importance [4]. Students who are on the path of self-determination, obtaining significant values and mutual understanding with others, relatives, and themselves are promising in creating a family [7, $8]$.

* Corresponding author: domeniko4@yandex.ru 
The family is the unit of society, which consists of support, love and respect. Unfortunately, many girls observe negative relationships in their families, which causes them to fear marriage. The reluctance to start a family and have children was influenced by a large increase in divorces, as well as violence within the family. It is your own family that can overcome the fear of others girls [9]. The stability of family relationships is a great example for overcoming the anxiety of marriage. This stability depends on the willingness of young girls to family, emotionally positive attitude to the family.

Girls believe that family life is boring, routine, monotonous, colorless. Now most people do not want to register an official marriage. Girls choose an easier way of cohabitation - "civil marriage". "Civil marriage" is an unregistered marriage, that is, the relationship between a woman and a man is not legally approved [10]. The girls have the opinion that this type of marriage is more simplified. Partners take on less responsibility and obligations, as such relationships are easier to break. And in legalized relationships, they distinguish confidence, reliability, constancy and replenishment in the family.

The value relations of the girl to the family arise due to objective and subjective social factors that represent the important importance of the family in society, the relationship between parents, personal characteristics, gender [1]. There is a need for a scientific study of these factors on the position of the family in the value orientations of girls, which will contribute to a better understanding of the mechanisms of the development of value orientations of girls in general[5].

The degree of development of the research problem: family and family values are in the focus of attention of domestic and foreign sciences: social psychology, pedagogy, philosophy, sociology. Scientists A. I. Antonov, E. A. Tulina and I. E. Kalabikhina considered the problems in single-parent families. A.V. Romanova and G. M. Tsinchenko studied the problems of young families. The study of the value-semantic sphere was carried out by A. N. Leontiev, M. Weber, V. N. Myasishchev, T. Parsons, and others [6].

\section{Materials and Methods}

On the basis of theoretical assumptions, we formulated the purpose of the study - to identify the value orientations of girls who are in an informal and official marriage. The hypothesis of the study was the assumption that there may be differences in the value-semantic sphere of girls who are in an informal marriage and girls who are in an official marriage, as well as the degree of satisfaction with marriage may differ in women who are in different types of family relationships.

To identify the differences in the value-semantic sphere of girls who are in an informal marriage and girls who are in an official marriage, as well as to determine the degree of satisfaction with marriage of women who are in different types of family relations, the following methods were used: to identify the value-semantic sphere of the individual "Value orientations "(M.Rokich). The method "Meaning-life orientations" (D. A. Leontiev) evaluates the source of the meaning of life, which can be found by a person in the future (goals), present (process), past(result) or in three components at once. Test - questionnaire of marriage satisfaction (V. V. Stolin, T. L. Romanova, G. P. Butenko).

Empirical object of research: a total of 50 people participated in the study. Girls who are in an informal marriage (25 people) and in an official marriage (25 people) were interviewed. The age of the subjects is from 18 to 30 years. The reliability of the obtained data was provided by mathematical statistics according to the Mann-Whitney U-test. For computer processing of the empirically obtained data, standard statistical programs were used: "Microsoft Excel 7.0" and STATISTIKA, Stat Soft" (version 6.1). 


\section{Results}

As a result of the study, 50 respondents were interviewed. All respondents were divided into two groups: girls who are officially married and in an informal marriage. Each group of the group studied value orientations, meaning-life orientations, and satisfactiondissatisfaction with marriage. Next, a comparison was made between the two groups. Below are the results for each of them.

The study was carried out using the method "Value orientations" by M. Rokich.

According to the data, it can be seen that in the terminal values of girls who are in an informal marriage, "Love", "Freedom", "Self-confidence" prevail. The highest indicator is the "Love" scale, girls are still on the threshold of marriage, when choosing a partner, criteria such as emotions, feelings of love are important to them. Thus, the girl prefers to act only on her own, without external pressure, and how important it is for her to treat herself, her partner and relatives with respect.

In girls who are officially married, "Love", "Happy family life", "Health" prevail. The scale of "Love" is a high indicator, as we said above, for girls who are in an informal marriage, emotions and feelings of love are important, but for married girls, it is important to keep this in their marriage. By getting married, their feelings have increased and being married, the girl wants a strong, harmonious family, filled with love and warmth.

It should be noted that the two groups were on the same level of "Development", as the girls mean by this: the value of disclosure, knowledge, beauty, good.

According to the data, it can be seen that in the instrumental values of girls who are not married, they value "Independence", "Cheerfulness", "Sensitivity"more. This suggests that the subjects prefer to be independent, free. And also important is tenderness, sensitivity and attention.

Married girls appreciate "Cheerfulness", "Good Manners", "Neatness". Therefore, this suggests that it is important for girls to know the rules of behavior in society, cleanliness in the house, conscientiousness.

In two groups, the "Cheerfulness" scale was chosen, the subjects treat life cheerfully, optimistically, joyfully, which makes them cheerful and lively. They have an optimistic attitude to life and life circumstances.

The differences in the two groups of value orientations were studied using the Mann Whitney U-test, which is designed to evaluate between two choices. In girls who are officially married, the scales of "Self-confidence" and "Freedom" prevail in the terminal values, and they are on the same level, and the scale of "Sensitivity" in the instrumental values. Thus, for girls in an official marriage, the importance of self-confidence, freedom and sensitivity is higher than for unmarried girls. These values may indicate that married girls focus on independence, delicacy, sensitivity and respect for themselves, their husband and loved ones.

From the data presented we can conclude that out of the 50 subjects with a high level reached $20 \%$, and the average level is $52 \%$, low $-28 \%$.

The results of the test of life-meaning orientations D. A. Leontiev showed that girls who are married, the overall meaningfulness of life is higher than that of girls, consisting of informal marriage, which indicates a higher confidence in themselves and in their abilities.

Next, the marriage satisfaction questionnaire test developed by V. V. Stolin, T. L. Romanova, and G. P. Butenko was conducted.

The analysis of the results showed that 50 young girls, 25 of whom are in an informal marriage, 25 in an official one, revealed: complete dissatisfaction $-4 \%$, significant dissatisfaction- $4 \%$, rather dissatisfaction-3 \%, rather satisfaction-20\%, significant satisfaction- $34 \%$, complete satisfaction- $32 \%$. 
According to the criterion H-Kruskal-Walis criterion, it was found that the level of satisfaction depends on the value orientations and life-meaning strategies of girls.

It is revealed that the low overall satisfaction with marriage is dominated by the value of "Happy life", the average overall satisfaction with marriage - the Overall indicator of meaningfulness of life, which indicates self - confidence and self-confidence, the high overall satisfaction - "Education", and the full overall satisfaction-goals in life, which indicates the purposefulness of the individual.

The overall correlation analysis presented in Table 1 for this sample showed that young girls in an official marriage value "Self-confidence" and "Sensitivity" more, while girls in an informal marriage value "Freedom" and "A happy family life". Also, girls who are married have a higher overall sense of meaning in their lives than girls who are in an informal marriage, which indicates a higher level of self-confidence and self-confidence. According to these indicators and the indicators of the methods, we can say that the data are reliable.

Table 1. Correlation analysis of the study/

\begin{tabular}{|c|c|c|c|c|}
\hline & $\begin{array}{c}\text { Informal } \\
\text { marriage } \\
\text { (secondary) }\end{array}$ & $\begin{array}{c}\text { Informal } \\
\text { marriage } \\
\text { (standard } \\
\text { deviation) }\end{array}$ & $\begin{array}{c}\text { Official } \\
\text { marriage } \\
\text { (secondary) }\end{array}$ & $\begin{array}{c}\text { Official } \\
\text { marriage } \\
\text { (standard } \\
\text { deviation) }\end{array}$ \\
\hline $\begin{array}{c}\text { a general } \\
\text { indicator of the } \\
\text { meaningfulness } \\
\text { of life }\end{array}$ & 91 & 19.18 & 112.48 & 17.02 \\
\hline goals in life & 27.44 & 0.61 & 35.2 & 0.58 \\
\hline $\begin{array}{c}\text { the process of } \\
\text { life }\end{array}$ & 25.68 & 7.85 & 31.08 & 6.04 \\
\hline $\begin{array}{c}\text { performance of } \\
\text { life }\end{array}$ & 22 & 7.95 & 27.84 & 7.09 \\
\hline $\begin{array}{c}\text { locus of } \\
\text { control-I }\end{array}$ & 18.52 & 6.78 & 23.04 & 5.35 \\
\hline $\begin{array}{c}\text { locus of } \\
\text { control-life }\end{array}$ & 26.92 & 4.54 & 33.2 & 3.09 \\
\hline freedom & 7.36 & 4.18 & 4.18 & 3.92 \\
\hline $\begin{array}{c}\text { happy family } \\
\text { life }\end{array}$ & 8.36 & 4.11 & 6.2 & 5.07 \\
\hline self-confidence & 7.04 & 4.52 & 10.48 & 4.42 \\
\hline sensitivity & 7.04 & 4.17 & 9.48 & 3.77 \\
\hline
\end{tabular}

\section{Discussion}

Girls who are in an official and unofficial marriage have formed different value orientations and life-meaning strategies, as well as levels of satisfaction with marriage.

On the basis of theoretical and empirical analysis, we found out that the girls who are officially married are dominated by the terminal values of the scale: "Self-confidence" and "Freedom" and they are on the same level, and the instrumental values of the scale "Sensitivity". Thus, for girls in an official marriage, the importance of self-confidence, freedom and sensitivity is higher than for unmarried girls. Girls who are married have a higher overall sense of meaning in their lives than girls who are in an informal marriage, which indicates a higher level of self-confidence and self-confidence. In low overall 
satisfaction with marriage, the value of "Happy life" prevails, in average overall satisfaction with marriage - the Overall indicator of meaningfulness of life, which indicates selfconfidence and self-confidence, in high overall satisfaction - "Education", and in full overall satisfaction-goals in life, which indicates the purposefulness of the individual.

A general correlation analysis of this sample showed that girls in an official marriage value "Self-confidence" and "Sensitivity" more, while girls in an informal marriage value "Freedom" and "A happy family life". According to these indicators and the indicators of the methods, we can say that the data are reliable.

\section{Conclusions}

Our research has led to the following conclusions. In this paper, we considered the valuesemantic sphere and the degree of satisfaction with marriage among girls who are in different types of family relations and (formal and informal marriage).

In the course of the theoretical study of the problem, works on the study of the valuesemantic sphere of the individual were analyzed, and various approaches to the study of the family were considered.

Theoretical and empirical studies were conducted, during which the following conclusions were made:

The realities of modern society are such that it is an extremely complex process of forming the values of the family and the union and the attitude towards them, in particular to the younger generation. Studying the value orientations, we can conclude that there may be differences in the value-semantic sphere in people. Psychologists have identified a set of factors that affect people. The leading ones are: the formation of value orientations through the penetration of social information into the psychological world of the child; In adolescence, a type of youth subculture arises, which is influenced by the main mechanisms of cultural transformation of a new type of value-information models.

We conducted an analysis of the literature on the problem, which helped us to draw the following conclusions. Value orientations can be represented as part of the internal structure of a person, which is fixed by life experience, experiences, that is, the only and unique system of values peculiar to any person. Girls who are married get satisfaction from the material support, attention, devotion, and tenderness of their spouse, and twenty and thirty-year-old girls who are in an informal marriage, the satisfaction of physical needs, care, money, and mutual understanding prevail.

Despite the fact that there are many approaches to the study of value orientations, foreign and domestic researchers still agree that value orientations determine a person's life position in relation to existing or emerging phenomena of reality.

In girls who are officially married, the terminal values are dominated by freedom and self-confidence, and in girls who are in an informal marriage, family life prevails. In girls who are officially married, sensitivity prevails in instrumental values. Girls who are married have a higher overall sense of meaning in their lives than girls who are in an informal marriage. Also, the girls of the two groups attach a specific meaning to the goals in life, which has a positive effect on the satisfaction of marriage.

Based on the conducted empirical research and the obtained statistical data, it can be argued that the hypotheses that there are differences in the value-semantic sphere, as well as in the degree of satisfaction with marriage in girls who are in an informal marriage, and girls who are in an official marriage have been confirmed.

This work will be of interest to practical psychologists and psychotherapists, as it addresses issues that affect family relationships, which are so often addressed by clients 1 


\section{References}

1. Yu.A. Zubok, The problems of modern development of young people at risk (Sotsis, 2017).

2. K.W. Kambarova, Young uny 11, 48 (2016).

3. A.P. Kuznetsov, Value orientation and installation in the field of family relations in boys and girls, well (Youth in science: new arguments, 2015).

4. A.G. Kharchev, The Family as a factor of socio cultural development of society (Nauka, Moscow, 2016).

5. N. Frude, Understanding Family Problems: A Psychological Approach (New York, Wiley, 2016).

6. S.T. Hauser, S.I. Powers, G.G. Noam, Adolescents an Their Families: Paths of Ego Development (Free Press, New York, 2016).

7. P. Noller, V. Callan, The Adolescent in the Family (Routledge, New York, 2015).

8. V.P. Shakhmatov, Young family: viability, demography, law (Book publishing house, Krasnoyarsk, 2015).

9. V.M. Tseluiko, Psychology of the modern family (St. Petersburg, 2015).

10. E. Swedenborg, Conjugal love (AST Astrel, Moscow, 2017).

11. Yu.I. Semenov, The origin of marriage and family (Moscow, 1974).

12. V. Moskalenko, Dependence-family disease (Moscow, 2018).

13. S.A. Wolchik, P. Karoly, eds., Children of Divorce: Empirical Perspectives on Adjustment (GardinerPress, New York, 2017).

14. N. Worden, Adolescents and Their Family: An Introduction Assessment and Intervention (Binghamton, NY, Haworth Press, 2016). 